\title{
The Digital World for Children and its Relationship with Personality Disorders: Exploring Emerging Technologies
}

$\underline{\text { https://doi.org/10.3991/ijet.v15i01.11412 }}$

\author{
Salwa Abdullah Al Majali \\ Al Ain University, Abu Dhabi, United Arab Emirates \\ Salwa.almajali@aau.ac.ae
}

\begin{abstract}
Nowadays, children live in the world of modern technologies, which have become an integral part of our daily life. Therefore, it is very important to study the influence of the digital world on the child, especially on his personality development. The impact of the digital world on personality disorder is not enough studied in the UAE and is relevant. The cause of personality disorder in an adult can be mental health problems as a child, namely, emotional instability, excessive fear and anxiety, behavioral problems. The purpose of our research is to evaluate the relationship between the dependence of children on the Internet and the mental health of a child. The study involved 463 students from public and private schools in Dubai aged from 8 to 16 years. Internet Addiction Test, IAT, C. Young (Kimberley S. Young, 1996) was used to determine the level of Internet addiction The Strength and Difficulties Questionnaire (SDQ, 2015) was used to determine the degree of psychological health of a child. Pearson's correlation analysis showed that there is a positive correlation between the level of Internet addiction and the child's psychological health, the Pearson correlation coefficient is 0.63 . The category of internet-addict has the highest rates on the criteria: emotional symptoms (61\%), peer relationship problems $(73 \%)$, hyperactivity (33\%), and behavioral problems (43\%). High rates of these criteria indicate that Internet-dependent children are characterized by aggressiveness, increased anxiety, depression, indifference to others, irresponsibility. In addition, they have problems with communication, excessive impulsiveness, and lack of desire to help others. This result indicates the presence of the negative impact of excessive use of the Internet on the psychological health of the child, which can cause personality disorder.
\end{abstract}

Keywords-Digital world, internet-addict, mental health, children, personality disorders.

\section{$1 \quad$ Introduction}

Computer, mobile phone, other digital devices, the Internet, social networks, IT tools over the past 20 years have radically changed the world around. They have become important means of activity and a significant means of communication for modern people (Plowman, 2010). Generations whose active socialization takes place under this reality are characterized by different authors as "digital generation", "network 
generation" and even "digital natives" (Palfrey, \& Gasser, 2011). Socialization of children today occurs not only in the material world and the familiar environment of social interactions, but also in the digital environment. And what is more, over time, the value of digital socialization only increases (Levy, 2009). One of the ways children learn is to observe their parents. Today's child can see that his/her parents use computer technology more often than they read books (Cooper, 2005). Studies on the impact of the use of information technology increased exponentially during the information age, ahead of only the growth of information technology itself. In the last century, the focus was on the impact of computer learning on the cognitive development of children (Wartella \& Jennings, 2000). Research on the cognitive, social, psychological, and physical implications of using the Internet for children and adolescents remains unanswered. (Jackson, 2008). Working with a computer develops attention, logical and abstract thinking. Developing computer games for children is a great way of self-education, the ability to use the Internet can become a good school of communication and skills in searching and selecting information (Chen, 2014). Examples of the negative effects of a computer on a child can be: children's aggression and cruelty, incorrect perception of the picture of the world, difficulties in communicating with other people (Strasburger, 2010). With proper approach and control of information and communication technology tools, (ICT) are an excellent means of learning and an addition to the learning process (Kim, LaRose, \& Peng, 2009 However, with uncontrolled use, these achievements of civilization can easily harm the full development of the child, his psychological and physical health, including causing various kinds of personality disorders. (Mittal, 2007, (Jackson, 2012).

Some mental health experts have expressed concerns that excessive use of the Internet can have a negative impact and contribute to the development of psychiatric symptoms (Bremer, 2005). There is more literature that the use of the Internet is associated with mental symptoms and syndromes. Numerous cases indicate that some active Internet users (that is, people using the Internet more than a few hours a day for nonwork-related activities) suffer from mental disorders (Treuer et al., 2001; Iftene et al. Al., 2004, Kendall, 2015).

In order to fully understand the phenomenon of personality disorders that occur in childhood and adolescence, it seems necessary to identify the factors and mechanisms that contribute to the development of a normal personality, and to identify regulatory behaviors, character traits and attitudes (Shedler, 2010). There are special criteria for the Diagnostic and Statistical Manual of Mental Disorder (Diagnostic and Statistical Manual of Mental Disorders), 5th edition (DSM-5) list of 10 distinctive types of personality disorder. (Whiteside, 2001). There are 10 types of personality disorders in DSM-5, divided into 3 clusters (A, B, and C) based on similar characteristics.

- Cluster A (unusual, strange, eccentric): paranoid, schizoid, schizotypal.

- Cluster B (dramatic, unstable): antisocial, borderline, hysterical, narcissistic.

- Cluster C (anxious, timid): avoidant, dependent, obsessive-compulsive (Saulsman, 2004; Gunderson, 2013).

One can speak about personality disorder when a complex of sufficiently stable stereotypes of thinking, perception, reaction and interpersonal relations become so 
pronounced, rigid and non-adaptive, that they disturb a person's lifestyle, interfere with work and/or affect interpersonal relations (Cloninger, 2008, (Krstic, 2017). The frequency or intensity of use of gadgets by children affects their mental and emotional development (Tabotabo, 2017). The symptoms of personality disorder in children are emotional instability, excessive fear and anxiety, behavioral problems (Gunderson, 2018). As a result of the analysis of the literature, it was determined that the data on the relationship between the use of gadgets, Internet resources and personality disorders of children aged 8 to 16 years are not sufficiently studied. Thus, the purpose of this study is to evaluate the relationship between the Internet addiction of children and their mental health.

\section{Methods}

This survey was conducted using an anonymous survey. The Internet Addiction Test (IAT) K. Young was used to determine the level of Internet addiction, a technique developed and tested in 1995 by Dr. Kimberley Young (Kimberley S. Young, 1996). The test consists of 20 questions. For each question, the subject must answer in accordance with the 5-point Likert scale (1-never, 2-rarely, 3-regularly, 4-often, 5-constantly). Points for all questions are summed up, determining the final value. Interpretation: 20 49 points - a regular Internet user. 50-79 points - there are some problems associated with excessive enthusiasm for the Internet. 80-100 points - Internet addiction.

To determine the degree of psychological health of a child, it was used The Strength and Difficulties Questionnaire (SDQ, 2015), which contains questions that can be used for children aged 8-16 years. SDQ has 25 psychological points divided into 5 scales: Emotional symptoms, Behavioral problems, Hyperactivity/Inattention, Peer relations problems and Prosocial behaviors that meet 3 options: never, rarely and often (SDQ, 2015).

\subsection{Participants}

In our study, 463 students from public and private schools in Dubai participated. Participation in the study was voluntary and with the permission of the parents who filled out the consent form. Table 1 shows the distribution of participants according to their demographic characteristics.

Table 1. Distribution of participants by demographic profile $(n=463)$

\begin{tabular}{|l|c|c|c|}
\hline \multicolumn{1}{|c|}{ Demographic characteristics } & Groups & $\mathbf{N}$ & $\mathbf{\%}$ \\
\hline \multirow{3}{*}{ Age in years } & $8-10$ & 169 & 40.8 \\
\cline { 2 - 4 } & $10-13$ & 189 & 36.5 \\
\cline { 2 - 4 } & $13-16$ & 105 & 22.6 \\
\hline \multirow{2}{*}{ Gender } & female & 207 & 44.7 \\
\cline { 2 - 4 } & male & 256 & 55.3 \\
\hline
\end{tabular}




\subsection{Statistical analysis}

Data analysis of our research was carried out in the STATISTICA system. For convenience, part of the data was converted to histograms developed in Origin 9. The size of the error is $2.9 \%$, some of the questionnaires were incorrectly filled out (for example, some respondents did not answer all the questionnaire questions). The data collected was analyzed using Pearson correlation coefficients to see any correlation between the frequency of using the Internet and the psychological signs of personality disorder. The statistical level was determined to be significant if the value of $p<0.05$.

\subsection{Research limitations}

The main limitation of the study was a limited sample, since the survey was conducted within the same city. Part of the questionnaire was incorrectly filled in. Besides, the Internet Addiction Test, IAT test) K. Young is a tool for self-diagnosis of pathological addiction to the Internet (regardless of the form of this addiction). However, it should be noted that the diagnostic category of Internet addiction has not yet been finally determined.

\section{$3 \quad$ Results}

According to the study, the most Internet-dependent children aged 10-13 years (18\%). 9\% less Internet dependent children in the 13-16 years category (see Table 2 ). This indicator suggests that children aged 10-13 years require more communication with their peers through social networks, video games. During this period, parents have less control over the use of various gadgets by the child.

Table 2. The degree of Internet dependence based on demographic characteristics $(n=463)$

\begin{tabular}{|l|c|c|c|c|c|}
\hline & Category & Normal user \% & Bordeline \% & Internet-addict \% & p value \\
\hline \multirow{2}{*}{$\begin{array}{l}\text { Respondents based } \\
\text { on age }\end{array}$} & $8-10$ & 69 & 30 & 11 & 0.001 \\
\cline { 2 - 6 } & $10-13$ & 39 & 57 & 18 & 0.001 \\
\cline { 2 - 6 } & $13-16$ & 34 & 43 & 9 & 0.001 \\
\hline \multirow{2}{*}{$\begin{array}{l}\text { Respondents based } \\
\text { on gender }\end{array}$} & male & 33 & 53 & 14 & 0.003 \\
\cline { 2 - 6 } & female & 42 & 46 & 12 & 0.001 \\
\hline
\end{tabular}

Confidence interval $\mathrm{p} \leq 0.005$

It should be noted that among children of the category of 8-10 years, the highest result $(69 \%)$ in the category of Normal user of Internet resources. This is due to the control of parents the using gadgets by their children. The child can control his behavior and perform his duties well enough: to pack a rucksack, prepare homework, make a bed, clean the room, wash and brush teeth, get dressed. Based on the results, it is worth noting that boys are more prone to Internet addiction. The difference between the normal attitude to the Internet and gadgets for girls is $10 \%$ higher. It can also be noted that the rate of Internet addiction in girls is $2 \%$ lower, $\mathrm{p}=0.001$. 


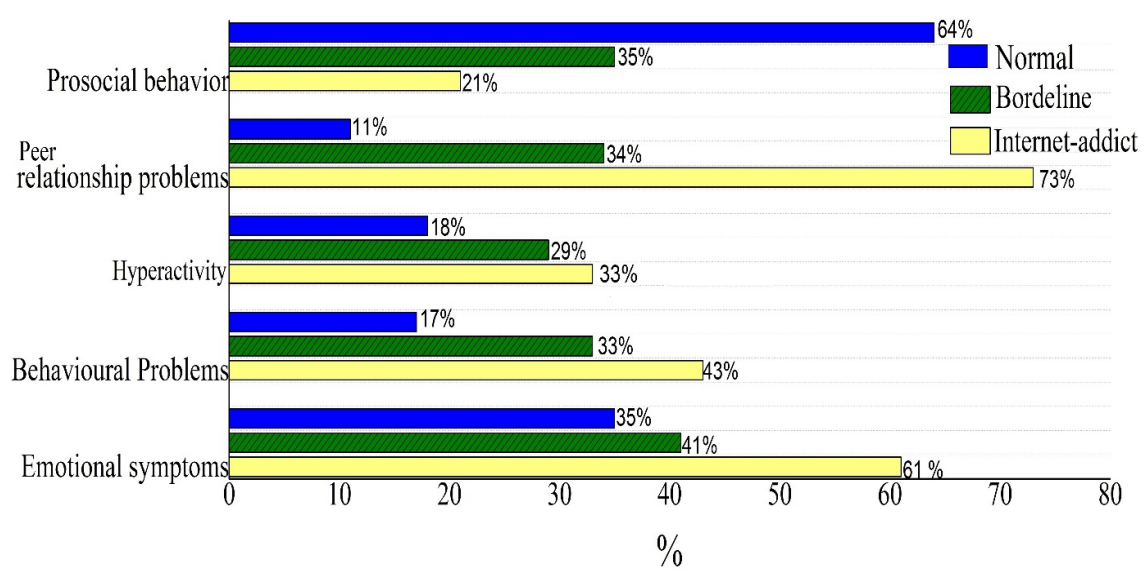

Fig. 1. The results of the relationship criterion of The Strengths and Difficulties Questionnaire (SDQ) and the level of Internet addiction.

The results of the comparison of groups of respondents with varying degrees of Internet addiction point to significant differences between them in a number of indicators of the child's psychological health. First of all, significant differences between groups of respondents with Normal user and Internet addict.

The results of the study show that the category of Internet-addict children has the highest rates according to the criteria for Emotional symptoms (61\%) and the criteria for Peer relations problems $(73 \%)$.

As can be seen in Figure 1, the criterion of Emotional symptoms in Internet-addict children is $26 \%$ higher than in the category Normal user. At the same time, the indicator of this category is quite high in the category of children Normal user (35\%). Children with a high criterion of Emotional symptoms often complain of a headache that they are not happy; they are also a lot of worried and fearful.

The high indicators of the Peer relationship problems criterion show that Internetaddict respondents prefer to play alone, they can scoff at others, and they themselves can be bullied. At the same time, their prosocial behaviors criterion has the lowest result of $21 \%$ in comparison with Normal user and Borderline. And in children, the Normal user is high (64\%.) A high indicator of this criterion indicates the children's desire to help others, cares about the younger ones, responsiveness and goodwill.

From the results it is clear that the respondents of the Borderline category also have quite high rates above $30 \%$. The result of the evaluation of the Behavioral problems criterion shows that the representatives of the Borderline category have it higher than the respondents with Normal user use by $16 \%$, and lower than the Internet-addict by only $9 \%$. This result indicates that respondents in the Borderline category also have problems with behavior. They can lie, be disobedient and aggressive. Based on the results, hyperactivity/inattention is less than $35 \%$ in all categories, but the highest in the Internet addict category in children, and the lowest in the category with a normal attitude to the Internet. The high rate of this criterion indicates that children are easily distracted, do not finish the job, are inattentive. 
The data collected was analyzed by applying Pearson correlation coefficients to see any correlation between the variables studied (see Table 3).

Table 3. Correlation between categories of Internet dependence and psychological characteristics.

\begin{tabular}{|l|c|c|c|}
\hline \multicolumn{1}{|c|}{ Variables } & Normal & Boardline & Addict \\
\hline Emotional symptoms & .51 & .55 & .83 \\
\hline Behavioural Problems & .53 & .61 & .82 \\
\hline Hyperactivity & .62 & .49 & .69 \\
\hline Prosocial behaviour & .59 & .52 & .53 \\
\hline Peer ralationship & .71 & .63 & .84 \\
\hline
\end{tabular}

** $\mathrm{p}>0.5$

As can be seen from the results of Table 3, there is a positive correlation of 0.63 between the categories of Internet dependence and the psychological health of the child. It is worth noting the high correlation between the criteria for Emotional symptoms, Behavioral Problems, as well as Peer relationship and Internet-addict children, which means that the Internet, as part of the digital world, can influence psychological characteristics and cause personal disorder.

\section{Discussion}

Studies show that using a computer for more than 30 hours a week for more than 10 years will increase the possibility of depression and dependence (Long, 2004). Other studies say that children who use gadgets for more than 2 hours per day have an increased risk of depression, and this risk increases with increasing viewing time (Wahyuni, 2019). Scientists have also determined that using too many gadgets causes depression in children at a certain age. It also causes mental health problems in children during childhood and adolescence. They may act in depression, or the worst of these symptoms of depression may be seen within a few days (Sundus, 2015). The study showed that adolescents with a problematic Internet use are more likely to suffer from emotional symptoms, behavioral symptoms, and problems of social adaptation, while adolescents with a normal Internet use have significantly higher grades in general and all parameters of life satisfaction. Among the participants who used the Internet excessively, the proportion of those who had low subjective performance was high. IA is associated with poor school performance (Chen \& Peng, 2008). Studies in China found statistically significant positive correlations between Internet addiction and interpersonal problems $(\mathrm{r}=0.43, \mathrm{P}<0.001)$ (Seo, 2009). According to the study, adolescents, who spend more time on a computer or mobile phone, were marked as "Internet dependent." The situation is aggravated by the fact that computer addiction is forming extremely quickly: on average, it takes no more than six months for a teenager to become computer addicted (Lee, 2018). 


\section{Conclusion}

As a result of the research, it can be concluded that excessive use of gadgets to access the Internet has a number of negative effects on the child as it was evidenced by the results of the study. There is a positive correlation between the criteria for the psychological health of children and the degree of dependence on the Internet, $p=0.63$. The category of Internet-dependent children has the highest rates on the criteria: Emotional symptoms (61\%), peer relations problems (73\%), hyperactivity/inattention (33\%), behavioral problems $(43 \%)$. At the same time, the result by the criterion of prosocial behavior is $21 \%$, for comparison, in the Normal user category, this indicator is $64 \%$. These results indicate that internet-dependent children are characterized by aggressiveness, increased anxiety, and depression. In addition, they have problems with communication, excessive impulsiveness, lack of desire to help others. There is a positive correlation between the criteria for mental health of children and the degree of dependence on the Internet, $p=0.63$. This means the Internet as part of the digital world can influence the psychological state of a child. High indicators of the mental health criteria presented in the study, in addition to prosocial behaviors, can cause a child's personality disorder. According to the study, the most Internet-dependent children aged 10-13 years $(18 \%)$. Normal attitude to the use of gadgets in order to access the Internet for children aged 8-10 years. It is also worth noting that boys are more Internet dependent (14\%) than girls $(12 \%)$.

\section{References}

[1] Chandrasena Premawardhena, N., ICT in the foreign language classroom in Sri Lanka: A journey through a decade. 10th World Conference on Computers in Education (WCCE 2013), Nicolaus Copernicus University, July 2-5 2013, Torun, Poland.pp 223-224.

[2] Chandrasena. Premawardhena, N. (2012). Introducing Computer Aided Language Learning to Sri Lankan Schools: Challenges and Perspectives. 15th International Conference on Interactive Collaborative Learning and 41st International Conference on Engineering Pedagogy (ICL \& IGIP), Villach, Austria. https://doi.org/10.1109/ICL.2012.6402118

[3] Bremer, J., 2005. The Internet and children: advantages and disadvantages. Child Adolesc. Psychiatr. Clin. N. Am. 14 (3), 405-428. https://doi.org/10.1016/j.chc.2005.02.003

[4] Cao, H., Sun, Y., Wan, Y., Hao, J., \& Tao, F. (2011). Problematic Internet use in Chinese adolescents and its relation to psychosomatic symptoms and life satisfaction. BMC public health, 11(1), 802. https://doi.org/10.1186/1471-2458-11-802

[5] Chen YF, Peng SS. University students' Internet use and its relationships with academic performance, interpersonal relationships, psychosocial adjustment, and self-evaluation. Cyberpsychol. Behav. 2008; 11: 467-469. https://doi.org/10.1089/cpb.2007.0128

[6] Chen, N. S., \& Hwang, G. J. (2014). Transforming the classrooms: innovative digital gamebased learning designs and applications. Educational Technology, Research and Development, 62(2), 125. https://doi.org/10.1007/s11423-014-9332-y

[7] Cloninger, C. R., \& Svrakic, D. M. (2008). Personality disorders. In The medical basis of psychiatry (pp. 471-483). Humana Press. https://doi.org/10.1007/978-1-59745-252-6 28

[8] Cooper, L. Z. (2005). Developmentally appropriate digital environments for young children. Library trends, 54(2), 286-302. https://doi.org/10.1353/lib.2006.0014 
[9] Gunderson, J. G., Herpertz, S. C., Skodol, A. E., Torgersen, S., \& Zanarini, M. C. (2018). Borderline personality disorder. Nature Reviews Disease Primers, 4, 18029. https://doi.org/10.1038/nrdp.2018.29

[10] Gunderson, J. G., Weinberg, I., \& Choi-Kain, L. (2013). Borderline personality disorder. Focus, 11(2), 129-145. https://doi.org/10.1176/appi.focus.11.2.129

[11] Iftene, F., Napoca, C., Roberts, N., 2004. Internet use in adolescents: hobby or avoidance. Can. J. Psychiatry 49 (11), 789-790.

[12] in korean adolescents. Comput Inform Nurs 2009, 27:226-233. https://doi.org/10. 1097/NCN.0b013e3181a91b3f

[13] Jackson, L. A. (2008). Adolescents and the Internet. In D. Romer \& P. Jamieson (Eds.), The changing portrayal of American youth in popular media (pp. 377-410). Annenberg Public Policy Center at the University of Pennsylvania, New York, Oxford University Press. https://doi.org/10.1093/acprof:oso/9780195342956.003.0014

[14] Jackson, L. A., Witt, E. A., Games, A. I., Fitzgerald, H. E., Von Eye, A., \& Zhao, Y. (2012). Information technology use and creativity: Findings from the Children and Technology Project. Computers in human behavior, 28(2), 370-376.https://doi.org/10. 1016/j.chb.2011.10.006

[15] Kendall, P. C., Carper, M. M., Khanna, M. S., \& Sue Harris, M. (2015). Computer Technology and Children's Mental Health. Emerging trends in the social and behavioral sciences: An interdisciplinary, searchable, and linkable resource, 1-16.https://doi.org/10. 1002/9781118900772.etrds0049

[16] Kim, J., LaRose, R., \& Peng, W. (2009). Loneliness as the cause and the effect of problematic Internet use: The relationship between Internet use and psychological well-being. CyberPsychology \& Behavior, 12(4), 451-455.https://doi.org/10.1089/cpb.2008.0327

[17] Krstic, S., Neumann, C. S., Roy, S., Robertson, C., Knight, R. A., \& Hare, R. D. (2017). Personality Disorders: Theory, Research, and Treatment (forthcoming).

[18] Lee, G. L., \& Morgan, H. (2018). Understanding children's attraction toward digital games and preventing their gaming addiction. US-China Education Review A, 8(1), 11-17. https://doi.org/10.17265/2161-623X/2018.1.002

[19] Levy, R. (2009). 'You have to understand words... but not read them': young children becoming readers in a digital age. Journal of Research in Reading, 32(1), 75-91. https://doi.org/10.1111/j.1467-9817.2008.01382.x

[20] Liu M, Wu L, Yao S. Dose-Response Association of Screen Time-Based Sedentary Behaviour In Children and Adolescent And Depression: A Meta-Analysis of Observational Studies. China. Br J Sports Med Published. 2015;0: 1-8

[21] Long JD, Stevens KR. Using technology to promote self-efficacy for healthy eating in adolescents. J Nurs Scholarsh. 2004; 36(2):134-9.https://doi.org/10.1111/j.1547$\underline{5069.2004 .04026 . x}$

[22] Master KM, Kaur CP, Narasimhan A, Mizrab N, Ali M, Shaik RB. Impact of Electronic Gadgets On Psychological Behavior Of Middle School Children In UAE. Uni Emirates Arab. Gulf Medical Journal. 2016;5 (S2): S54-S60.

[23] Mittal, V. A., Tessner, K. D., \& Walker, E. F. (2007). Elevated social Internet use and schizotypal personality disorder in adolescents. Schizophrenia research, 94(1-3), 50-57. https://doi.org/10.1016/j.schres.2007.04.009

[24] Palfrey, J. G., \& Gasser, U. (2011). Born digital: Understanding the first generation of digital natives. Read How You Want.

[25] Plowman, L., McPake, J., \& Stephen, C. (2010). The technologisation of childhood? Young children and technology in the home. Children \& Society, 24(1), 63-74). https://doi.org/10.1111/j.1099-0860.2008.00180.x 
[26] Saulsman, L. M., \& Page, A. C. (2004). The five-factor model and personality disorder empirical literature: A meta-analytic review. Clinical psychology review, 23(8), 1055-1085. https://doi.org/10.1016/j.cpr.2002.09.001

[27] Seo M, Kang HS, Yom YH: Internet addiction and interpersonal problems

[28] Shaw, Lindsay H., and Larry M. Gant. "In defense of the Internet: The relationship between Internet communication and depression, loneliness, self-esteem, and perceived social support." Internet Research 28.3 (2004).

[29] Shedler, J., Beck, A., Fonagy, P., Gabbard, G. O., Gunderson, J., Kernberg, O., \& Westen, D. (2010). Personality disorders in DSM-5. American Journal of Psychiatry, 167(9), 10261028. https://doi.org/10.1176/appi.ajp.2010.10050746

[30] Strasburger, V. C., Jordan, A. B., \& Donnerstein, E. (2010). Health effects of media on children and adolescents. Pediatrics, 125(4), 756-76. https://doi.org/10.1542/peds.2009-2563

[31] Sundus M. The Impact of Using Gadgets on Children. Journal of Depression and Anxiety. 2018;7 (1):1-3.

[32] Tabotabo LM. Factors Contributing to Excessive Use of Screen Gadgets and Its Effect to Social and Emotional Functioning. Asian Journal of Mathematical Sciences (AJMS) 2017;1(02)

[33] Treuer, T., Fabian, Z., Furedi, J., 2001. Internet addiction associated with features of impulse control disorder: Is it a real psychiatric disorder? J. Affect. Disord. 66 (2-3), 283. https://doi.org/10.1016/S0165-0327(00)00261-5

[34] Wahyuni, A. S., Siahaan, F. B., Arfa, M., Alona, I., \& Nerdy, N. (2019). The Relationship between the Duration of Playing Gadget and Mental Emotional State of Elementary School Students. Open access Macedonian journal of medical sciences, 7(1), 148. https://doi.org/10.3889/oamjms.2019.037

[35] Wartella, E. A., \& Jennings, N. (2000). Children and computers: New technology, old concerns. In The future of children: Children and computer technology, 10, Fall/ Winter 2000. https://doi.org/10.2307/1602688

[36] Whiteside, S. P., \& Lynam, D. R. (2001). The five-factor model and impulsivity: Using a structural model of personality to understand impulsivity. Personality and individual differences, 30(4), 669-689. https://doi.org/10.1016/S0191-8869(00)00064-7

[37] Young, K. S. (1996). Internet addiction: The emergence of a new clinical disorder. Paper presented at the 104th annual meeting of the American Psychological Association, August 18, 1996. Toronto, Canada.

[38] Youth in Mind. The Strengths and Difficulties Questionnaire. 2015. [Diakses pada tanggal: 28 Juli 2018].

\section{$7 \quad$ Author}

Salwa Abdullah Al Majali has done her PhD. She is an Assistant Professor, Applied Psychology Department at Al Ain University, Abu Dhabi, UAE.

Email: Salwa.almajali@aau.ac.ae

Article submitted 2019-07-31. Resubmitted 2019-09-17. Final acceptance 2019-09-21. Final version published as submitted by the authors. 